\title{
Correction to: Is bridging vein rupture/thrombosis associated with subdural hematoma at birth?
}

\author{
Marion Bartoli $^{1} \cdot$ Inès Mannes $^{1,2} \cdot$ Nadia Aikem $^{3} \cdot$ Caroline Rambaud $^{4} \cdot$ Paul de Boissieu $^{5} \cdot$ Catherine Adamsbaum $^{1,2}$
}

Published online: 1 February 2022

(c) The Author(s), under exclusive licence to Springer-Verlag GmbH Germany, part of Springer Nature 2022

\author{
Correction to: Pediatric Radiology (2022) \\ https://doi.org/10.1007/s00247-021-05255-w
}

A citation, \#19 (Rey-Salmon et al.), below, was omitted from the published article. The correct numbering of the citations is presented here:

19. Rey-Salmon C, de Boissieu P, Teglas JP, Adamsbaum C (2020) Abusive head trauma in day care centers. Pediatrics 146:e2020013771

20. Maxeiner H (2001) Demonstration and interpretation of bridging vein ruptures in cases of infantile subdural bleedings. J Forensic Sci 46:85-93

21. Cheshire EC, Malcomson RDG, Sun P et al (2018) A systematic autopsy survey of human infant bridging veins. Int J Legal Med 132:449-461

22. Han H, Tao W, Zhang M (2007) The dural entrance of cerebral bridging veins into the superior sagittal sinus: an anatomical comparison between cadavers and digital subtraction angiography. Neuroradiology 49:169-175

23 Monea AG, Baeck K, Verbeken E et al (2014) The biomechanical behaviour of the bridging vein - supe rior sagittal sinus complex with implications for the mechanopathology of acute subdural haematoma. J Mech Behav Biomed Mater 32:155-165

24 Migueis GFJ, Fernandes FAO, Ptak M et al (2019) Detection of bridging veins rupture and subdural haema

The original article can be found online at https://doi.org/10.1007/ s00247-021-05255-w

Catherine Adamsbaum

catherine.adamsbaum@aphp.fr

1 Pediatric Radiology Department, AP-HP, Bicêtre Hospital, 94270 Le Kremlin Bicêtre, France

2 Paris-Saclay University, Le Kremlin Bicêtre, France

3 Radiology Department, AP-HP, A Béclère Hospital, Clamart, France

4 Forensic Unit, AP-HP, Raymond Poincaré Hospital, Garches, France

5 Epidemiology and Public Health Department, AP-HP, Bicêtre Hospital, Le Kremlin Bicêtre, France toma onset using a finite element head model. Clin Biomech 63:104-111

25. Choudhary AK, Servaes S, Slovis TL et al (2018) Con sensus statement on abusive head trauma in infants and young children. Pediatr Radiol 48:1048-1065

26. Cohen MC, Scheimberg I (2009) Evidence of occurrence of intradural and subdural hemorrhage in the perina tal and neonatal period in the context of hypoxic ischemic encephalopathy: an observational study from two refer ral institutions in the United Kingdom. Pediatr Dev Pathol 12:169-176

27. Byard RW, Blumbergs P, Rutty G et al (2007) Lack of evidence for a causal relationship between hypoxicischemic encephalopathy and subdural hemorrhage in fetal life, infancy, and early childhood. Pediatr Dev Pathol 10:348-350

28. Hong HS, Lee JY (2018) Intracranial hemorrhage in term neonates. Childs Nerv Syst 34:1135-1143

29. Dunbar M, Kirton A (2019) Perinatal stroke. Semin Pediatr Neurol 32:100767

This correction also necessitates correction of the callouts to several citations. The correct citation callouts are as below:

This result also has major implications for understanding the cause of neonatal subdural hematomas, which are most likely not from bridging vein rupture/thrombosis, in contrast to those seen in abuse [25].

According to Cohen and Scheimberg [26], anoxicischemic encephalopathy leads to increased pressure in the veins and oozing into the subdural space.

However, our study found no statistically significant association between subdural hematoma and hypoxicischemic encephalopathy, in line with the postmortem study by Byard et al. [27], which found no subdural hematomas in 82 newborns with anoxic-ischemic encephalopathy. 
Looking at other intracranial hemorrhages, our results agree closely with those of Hong et al. [28], with an $11 \%$ prevalence of subarachnoid hemorrhage (compared to $7 \%$ in Hong's study) and a 7.5\% prevalence of intraparenchymal hemorrhage (versus 9\% in Hong's study).

The prevalence of perinatal stroke $(9 \%)$ was lower than that found by Dunbar et al. [29] (1 per 1,600-2,300 live births) because the newborns in our study were less than
10 days old, whereas Dunbar et al. included newborns less than 28 days old.

The original article has been corrected.

Publisher's note Springer Nature remains neutral with regard to jurisdictional claims in published maps and institutional affiliations. 